\title{
TNFAIP3 inhibits migration and invasion in nasopharyngeal carcinoma by suppressing epithelial mesenchymal transition
}

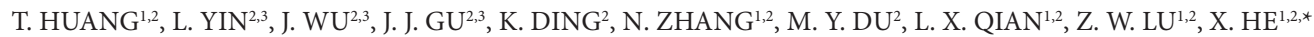 \\ ${ }^{1}$ The Fourth Clinical School of Nanjing Medical University, Nanjing, Jiangsu, China; ${ }^{2}$ Department of Radiation Oncology, Nanjing Medical Uni- \\ versity Affiliated Cancer Hospital, Cancer Institute of Jiangsu Province, Nanjing, Jiangsu, China; ${ }^{3}$ Research Center of Clinical Oncology, Nanjing \\ Medical University Affiliated Cancer Hospital, Cancer Institute of Jiangsu Province, Nanjing, Jiangsu, China
}

*Correspondence: hexiaBM@163.com

Received August 3, 2016 / Accepted November 22, 2016

\begin{abstract}
TNF alpha induced protein 3 (TNFAIP3), a member of zinc finger protein family, is a gene whose expression level is promptly induced by the tumor necrosis factor. In this study, the clinical significance of TNFAIP3 was analyzed based on available samples in The Cancer Genome Atlas database. TNFAIP3 downregulation was associated with distant metastasis and worse patient prognosis. TNFAIP3-overexpressing and TNFAIP3-knockdown NPC cell line models were established through plasmid-mediated overexpression and small interfering RNA (siRNA), respectively. Cell migration and invasion capacities were evaluated by wound-healing and transwell assays. Functional studies indicated that TNFAIP3 knockdown promoted migration and invasion, whereas TNFAIP3 overexpression alleviated these functions. Western blot analysis was used to examine protein changes from TNFAIP3 overexpression and knockdown, in which TNFAIP3 promoted the protein expression of E-cadherin and suppressed vimentin expression. Our data suggested that TNFAIP3 inhibited migration and invasion by suppressing epithelial mesenchymal transition in NPC.
\end{abstract}

Key words: nasopharyngeal carcinoma, TNFAIP3, invasion, metastasis

Nasopharyngeal carcinoma is characterized by high metastasis as well as invasion with high incidence in southern China and Southeast Asia $[1,2]$. About $90 \%$ of the patients with NPC at the initial encounter have lymph node metastases, which is closely related to poor prognosis [3]. With improved chemoradiotherapy, recent advances have been achieved in the local control of NPC; however metastasis remains to be the main cause for shorter survival time of NPC, especially in advanced stage patients $[4,5]$. Thus, a deeper understanding of the molecular mechanism that regulates invasion and metastasis in NPC is urgently needed.

Mounting evidence demonstrates that TNF alpha induced protein 3 (TNFAIP3) is a significant regulator of inflammation and immunity, which play important roles in the modulation of immune response to pathogens and the development of inflammatory and autoimmune disease [6-8]. Moreover, TNFAIP3 has been shown to be involved in several tumor biological features, including tumor radiosensitization [9], drug resistance [10], and cell proliferation [11]. However, few studies have investigated the role of TNFAIP3 in migration and invasion of NPC.
In the current study, we demonstrate that TNFAIP3 expression tends to be downregulated in NPC tissues and is closely associated to patient prognosis. Moreover, we confirmed that TNFAIP3 inhibits NPC migration and invasion by suppressing epithelial-mesenchymal transition (EMT) in vitro. Our findings suggest that TNFAIP3 may act as a valuable target in personalized therapeutic strategies for NPC patients.

\section{Patients and methods}

Patients and samples. Clinicopathological data were retrieved from The Cancer Genome Atlas (TCGA) database (https://portacancergenome.nih.gov/publications and genome-cancer.ucsc.edu/proj/site). Samples without completed data for analysis were excluded.

Cell lines and culture conditions. NPC cell lines originated from Research Center of Clinical Oncology of the Affiliated Jiangsu Cancer Hospital, Nanjing Medical University, Nanjing, China. The cells were propagated in RPMI 1640 medium 
(Hyclone, Logan, UT, USA) containing 10\% FBS (Gibco BRL, Gaithersburg, MD, USA) and $1 \%$ antibiotic (Gibco BRL), and were incubated at $37^{\circ} \mathrm{C}$ with $\mathrm{CO} 2$ saturated.

RNA sample preparation. Total RNA was extracted using TRIzol reagent (Invitrogen, Burlington, ON, Canada) according to manufacturer's protocol. RNA yield and purity was determined by measuring the absorbance (Abs) at 260 and $280 \mathrm{~nm}$. Only RNA samples with Abs260/Abs280 nm ratio of $>1.8$ were used.

Cell transfection. CNE-1 and CNE-2 cells were transfected with TNFAIP3-siRNA (RiboBio Guangzhou, China) and TNFAIP3 ORF clone (GeneCreate Biological Engineering Co., Ltd Wuhan, China) according to manufacturer's protocol. TNFAIP3 siRNAs were synthesized by RiboBio (Guangzhou, China). The targeting sequences were as follows: si-TNFAIP3-1, 5'- GCACCATGTTTGAAGGATA-3' and si-TNFAIP3-2, 5'- CAGCATGAGTACAAGAAAT - $3^{\prime}$. To minimize the possibility of off-target effects, siRNA-1 and siRNA-2 were cotransfected into NPC cell lines.

Quantitative reverse transcription-polymerase chain reaction analysis. According to manufacturer's instructions, total RNA was purified by using TRIzol reagent (Invitrogen, Carlsbad, CA). Then, $2 \mu \mathrm{g}$ of total RNA ,according to manufacturer's instructions, was reversetranscribed using Moloney murine leukemia virus reverse transcriptase (Promega, Madison, WI, USA). Expression levels of mRNAs were amplified using SYBR Green quantitative RT-PCR (qRT-PCR) on an ABI7300 real-time PCR machine (Applied Bio-systems). The expression of TNFAIP3 and $\beta$-actin was examined using the following specific primers: $5^{\prime}$-TGTGTATCGGTGCATGGTTTTA$3^{\prime}$ and $5^{\prime}$-TCCTCAGGCTTTGTATTTGAGC-3' and $5^{\prime}-$ GGACTTCGAGCAAGAGATGG-3' and 5'-AGCACTGTGTTGGCGTACAG-3', respectively. All reactions were performed in triplicate for each sample.

Cell wound healing assay. NPC cells were cultured in six-well plates $\left(1-1.5 \times 10^{5}\right.$ cells per well) and transfected with TNFAIP3-siRNA and TNFAIP3 ORF clone. When the cells reached $80 \%-90 \%$ confluence, a single wound was created in the center of the cell monolayer using a T-200-Y pipet tip. Wound areas were visualized under an optical microscope with a magnification of $100 \times$. Cell migration capability was examined by gap closure.

Migration and invasion assays. For transwell migration assays, CNE1 or CNE2 transfected cells $\left(5 \times 10^{3}\right)$ were plated in the top chamber with the non-coated membrane (24-well insert; pore size, $8 \mu \mathrm{m}$; BD Biosciences, San Jose, CA, USA). For invasion assays, CNE1 or CNE2 transfected cells $(5 \times$ $\left.10^{4}\right)$ were plated in the top chamber with coated membrane. In both assays, cells were plated in the top chamber in medium with $1 \%-2 \%$ serum; the lower chamber was filled with $20 \%$ FBS. After $24-48 \mathrm{~h}$ of incubation, cells that invaded through the membrane were fixed with $4 \%$ paraformaldehyde and stained with crystal violet. Cells were counted in five random fields in each well under a microscope at $100 \times$ magnification [12]. Three independent experiments were performed.

Western blot analysis. NPC cells were harvested and prepared in RIPA buffer (Beyotime, Shanghai, China) after $48 \mathrm{~h}$ of transfection. A total of 16-22 $\mathrm{mg}$ of protein from each sample was used for Western blot. Primary antibodies used in this study included monoclonal anti-TNFAIP3 (1:1000; Abcam, HK), anti-vimentin (1:1000; Cell Signaling Technology, USA), anti-E-cadherin (1:1000; Cell Signaling Technology, USA). $\beta$-actin (1:1000; Cell Signaling Technology, USA) was used as loading control. Immunoreactive bands were visualized using ECL detection reagent (Millipore, Billerica, MA, USA). All data analyses were repeated independently three times.

Statistical analysis. Statistical analyses were performed using Student's t-test and one-way ANOVA using GraphPad Prism 5.0 software and SPSS 13.0. Data are presented as mean \pm standard deviation (SD) of three independent experiments. Differences were considered significant at $P<0.05$.

\section{Results}

TNFAIP3 downregulation is associated with distant metastasis and poor patient prognosis. We analyzed clinicopathological data retrieved directly from TCGA. TNFAIP3 showed a negative correlation with distant metastasis of patients, in which low expression of TNFAIP3 was observed more frequently in distant metastatic group than in nonmetastatic group (Figure 1A). The cutoff value of TNFAIP3, as determined by receiver-operating characteristic analysis, was used to differentiate between high and low TNFAIP3 level among NPC patients (Figure 1B). Kaplan-Meier survival analysis was performed on patients based on TNFAIP3 expression levels. The results revealed that low TNFAIP3 level was associated with worse overall survival of patients (Figure 1C). A univariate Cox regression analysis confirmed that TNFAIP3 expression level, perineural invasion, and lymph node classification significantly affected overall survival of patients. Multivariate Cox regression analysis showed that low TNFAIP3 expression level and perineural invasion were independent predictors of reduced overall survival of patients (Supplementary Table 1). All together, these results indicate that TNFAIP3 downregulation may be involved in metastasis and prognosis.

TNFAIP3 inhibits cell invasion and migration in NPC cell lines. To investigate whether TNFAIP3 affects the migration and invasion of NPC cells, CNE- 1 and CNE- 2 cells were transfected with TNFAIP3 ORF clone and TNFAIP3-siRNA. The successful knockdown of ADAM17 in NPC cells was confirmed by qRT-PCR (Figure 2A). The cells were subjected to a wound-healing assay. In this test, TNFAIP 3 overexpression noticeably slowed down NPC cell migration in the scratched "wound" at the edges of CNE-1 and CNE-2 cells. Knockout of TNFAIP3 enhanced NPC cells migration capability (Figure 2B). The transfected cells were further cultured on a transwell 
A

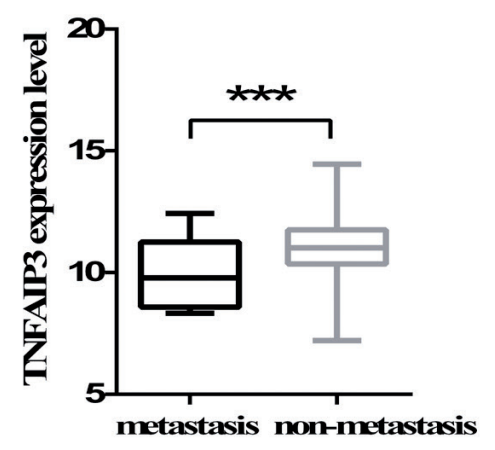

B

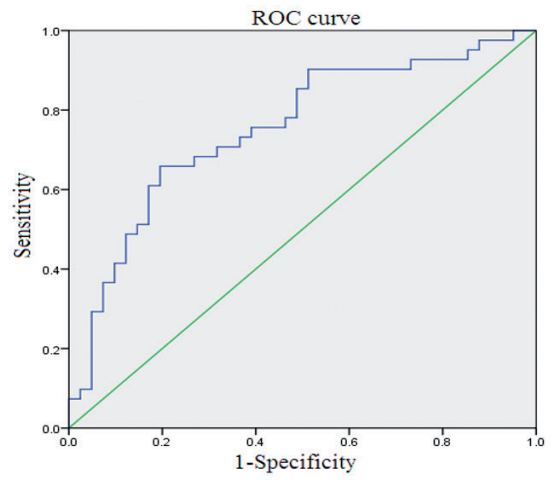

C

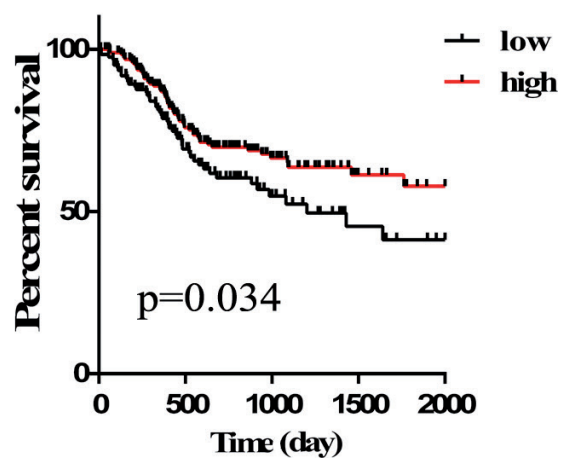

Figure 1. TNFAIP3 downregulation is associated with worse patient prognosis. (A) TNFAIP3 mRNA expression levels in the distant metastatic and nonmetastatic groups. (B) Receiver-operating characteristic analysis was performed to determine the cutoff value of TNFAIP3. (C) Patients with low TNFAIP3 expression had significantly worse overall survival than those with high TNFAIP3 expression. Log-rank test was used.

$\mathbf{A}$

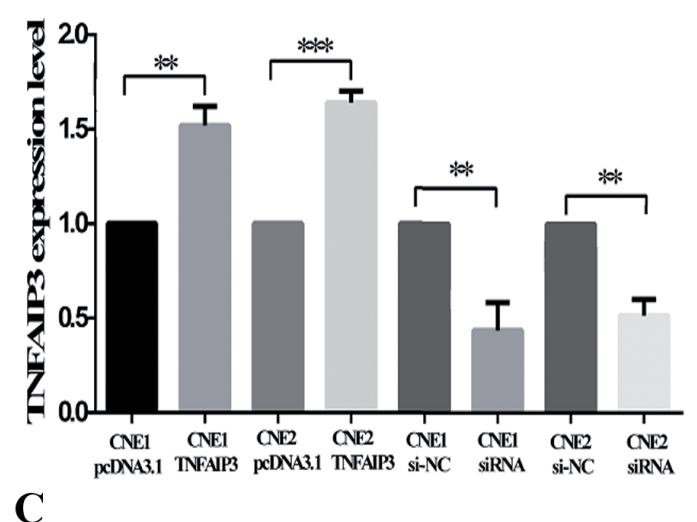

C
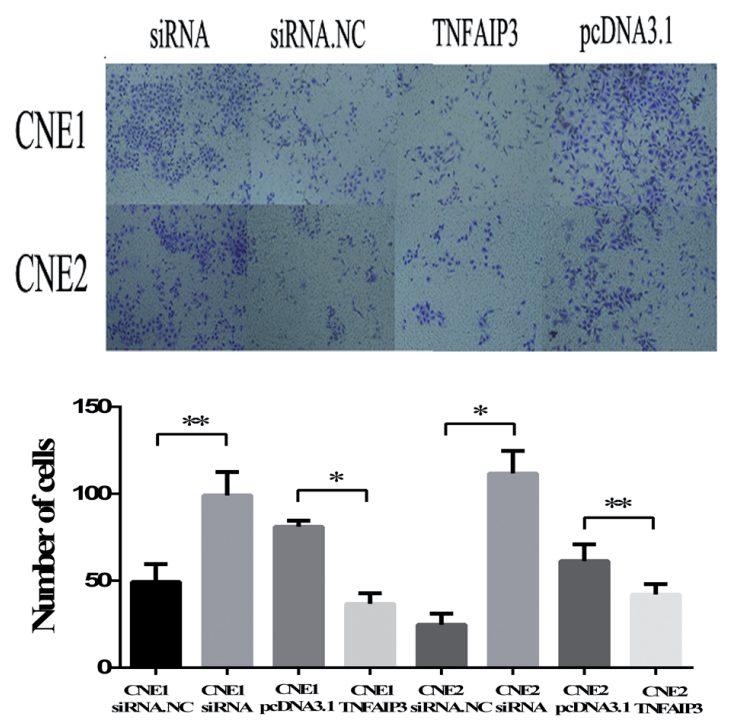

B

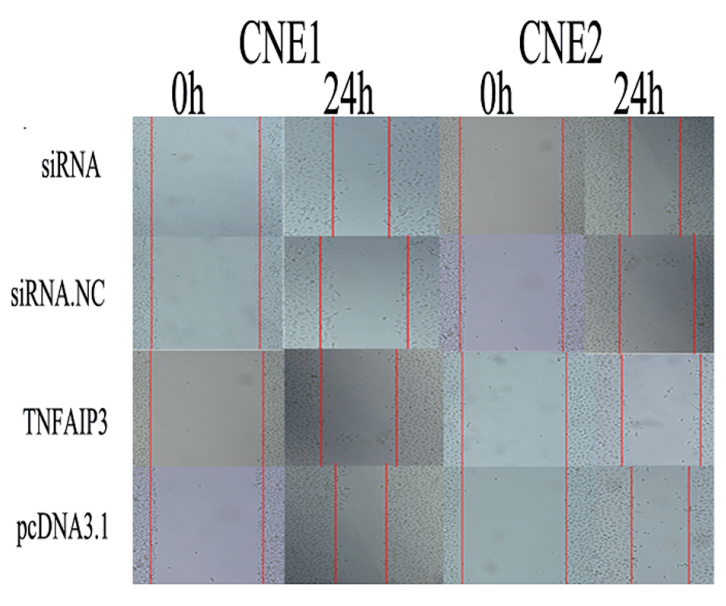

D
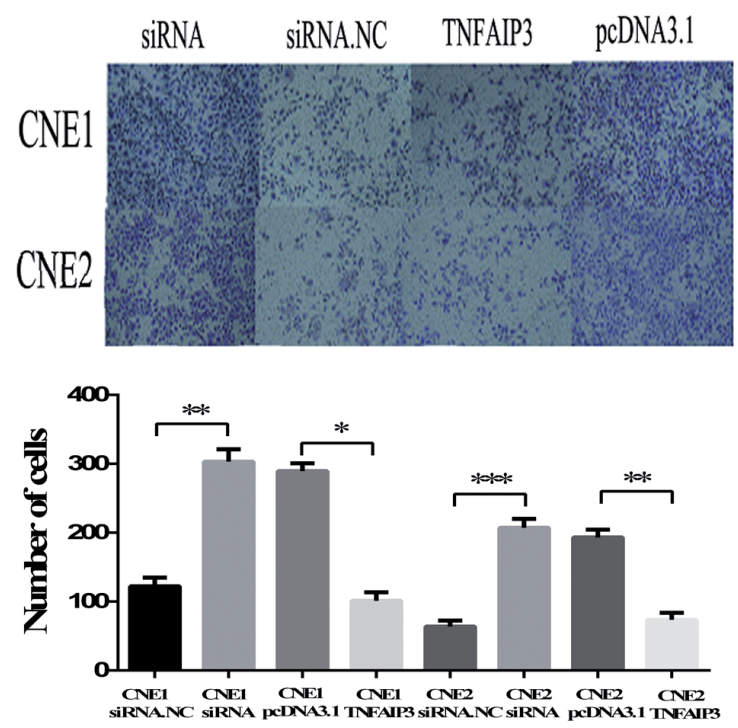

Figure 2. TNFAIP3 inhibits cell invasion and migration in NPC cell lines. (A) Quantification of TNFAIP3 mRNA expression by qRT-PCR. (B) Effect on migration by wound-healing assays. (C) Effect on migration by transwell assays. (D) Effect on invasion by transwell assays. 
apparatus. As shown in Figure 2C, the numbers of migrated cells were significantly less in the TNFAIP3-overexpressing cells. The number of migrated cells was significantly more in TNFAIP3-siRNA transfected cells. A matrigel model was established to examine the role of TNFAIP3 in NPC cell invasion. The number of invaded cells significantly decreased in cells transfected with TNFAIP3 ORF clone. As expected, knockdown of TNFAIP3 expression significantly promoted CNE1 and CNE2 invasion (Figure 2D). In conclusion, these data suggest that TNFAIP3 inhibits migration and invasion in NPC cells.

TNFAIP3 inhibits epithelial mesenchymal transition in NPC cells. EMT is closely related to tumor migration and invasion. A key molecular feature in EMT is the downregula- tion of E-cadherin and upregulation of vimentin. As such, we examined the expression levels of these two proteins and found that knockdown of TNFAIP3 significantly promoted the protein expression of vimentin and suppressed the expression of E-cadherin (Figure 3). In addition, TNFAIP3 overexpression promoted E-cadherin expression and suppressed vimentin expression. Thus, TNFAIP3 suppressed cell migration and invasion in NPC by inhibiting EMT.

\section{Discussion}

TNFAIP3 is identified as a gene whose expression level is promptly induced by the tumor necrosis factor. It is a zinc finger protein and plays an important role in cytokine-me-

A

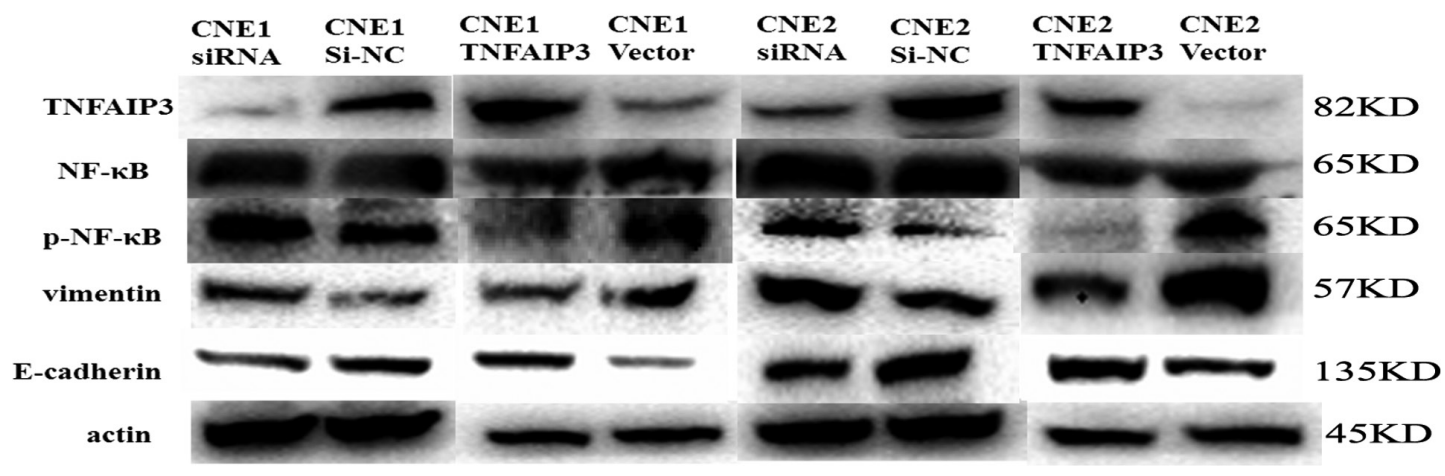

B
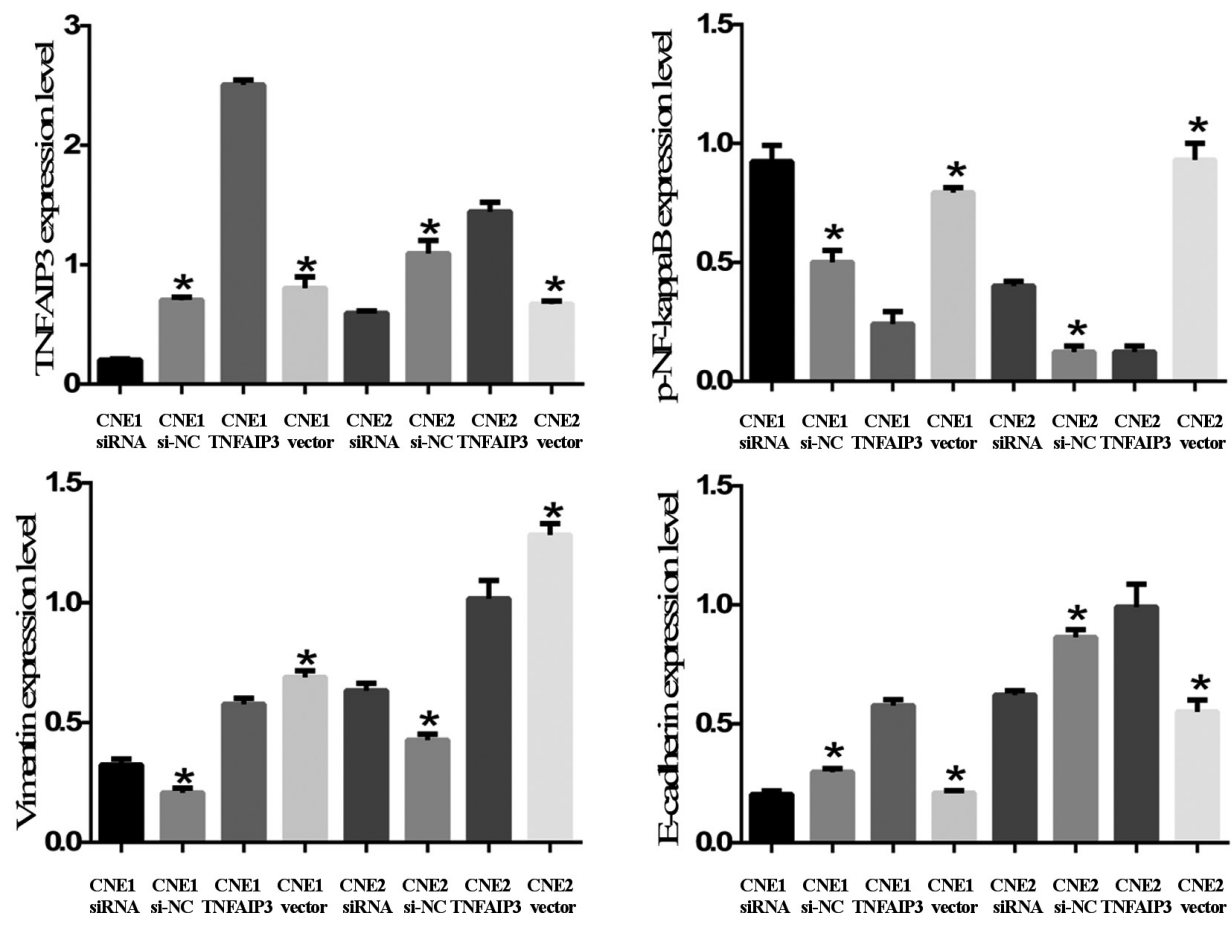

Figure 3. TNFAIP3 depresses EMT in NPC cells. (A) Western blot analysis to detect the expression of $\beta$-catenin, vimentin, E-cadherin, and TNFAIP3. (B) The relative protein expression levels were represented as columns. 
Table 1. Univariate and multivariate analyses of prognostic factors for overall survival using Cox proportional hazards regression model $(\mathrm{N}=321)$

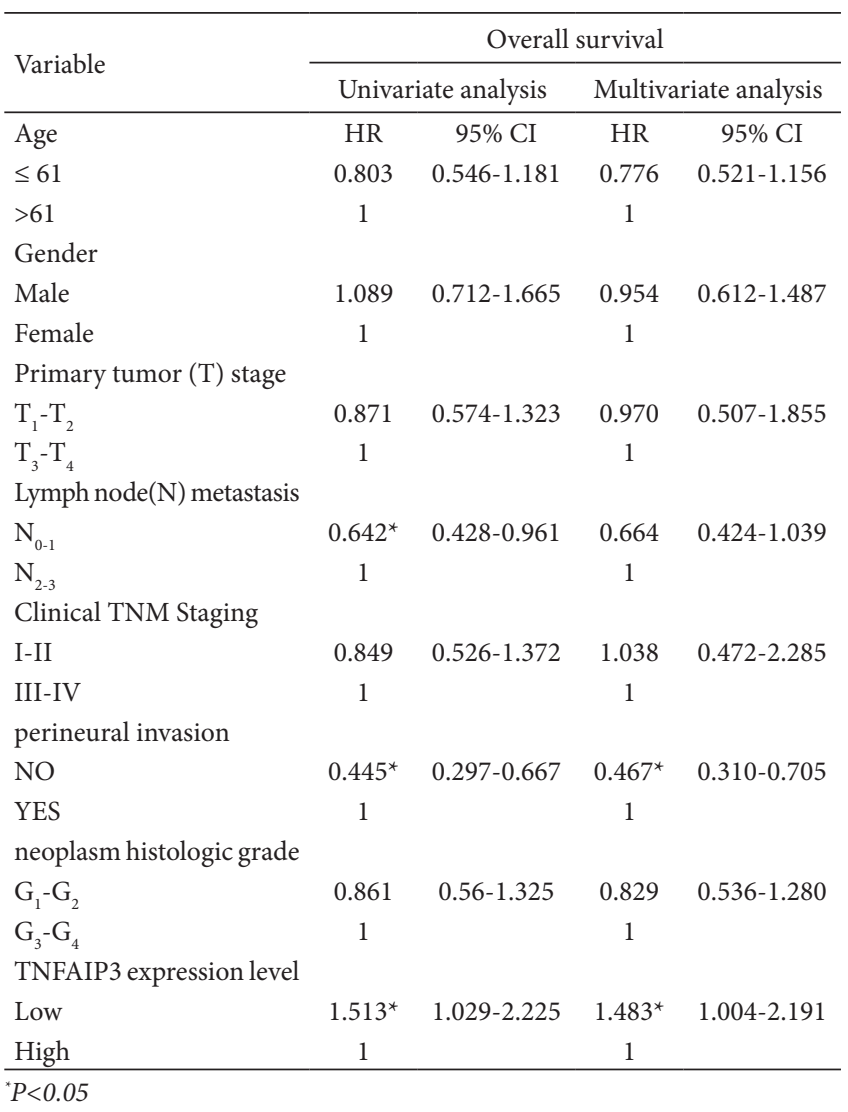

diated immune and inflammatory responses $[13,14]$. Some studies have shown that TNFAIP3 acts an important tumor suppressor in several malignancies. TNFAIP3 suppresses hepatocellular carcinoma proliferation through inhibition of Twist1 expression. TNFAIP3 deletion is tightly related with Epstein-Barr virus-associated lymphoproliferative disorders/lymphomas [15]. TNFAIP3 has also been proposed to function as a tumor suppressor in several human B-cell lymphomas. Moreover,TNFAIP3 takes part in cell differentiation in dendritic cell [16]. Indeed, the highest level of expression was observed in CNE1 (well-differentiated squamous cell carcinoma) and the highest level of expression was observed in C666 (undifferentiated squamous cell carcinoma, Supplementary Figure 1).

Low expression of TNFAIP3 was observed more frequently in the distant metastatic group than in the nonmetastatic group. Thus, we hypothesize that TNFAIP3 is involved in the NPC cell invasion and migration.

We further provide data indicating that knockdown of TNFAIP3 significantly stimulated migration and invasion, whereas TNFAIP3 overexpression inhibited migration and invasion in NPC cells. EMT, a key promoting factor for cancer invasion and migration, results in the downregula- tion of epithelial marker and upregulation of mesenchymal markers toward mesenchymal phenotype [17-19]. Mounting evidence suggests that EMT is a vital prerequisite for invasion and migration in various cancer [18, 20-22]. In the present study, epithelial marker E-cadherin was found to be upregulated, whereas mesenchymal marker vimentin was downregulated in TNFAIP3-overexpressing cells. On the other hand, E-cadherin was downregulated and vimentin was upregulated in cells expressing less TNFAIP3. Thus, TNFAIP3 was demonstrated to alleviate an EMT-like phenotypic transition.

In summary, our data revealed that TNFAIP3 is downregulated in NPC and serves as an independent predictor for patient survival. Our study is the first to demonstrate a significant role of TNFAIP3 in NPC cell invasion and migration, indicating that it is a molecular marker and a vital therapeutic target for NPC management.

Supplementary information is available in the online version of the paper.

Acknowledgments: This study was supported by the JiangSu Clinical Medicine Science and Technology Special Fund (No. BL2014091).

\section{References}

[1] NI C, CHEN Y, ZENG M, PEI R, DU Y et al. In-cell infection: a novel pathway for Epstein-Barr virus infection mediated by cell-in-cell structures. Cell Res 2015; 25: 785-800. https://doi. org/10.1038/cr.2015.50

[2] WU VW, LAM YN. Radiation-induced temporo-mandibular joint disorder in post-radiotherapy nasopharyngeal carcinoma patients: assessment and treatment. J Med Radiat Sci 2016; 63: 124-132. https://doi.org/10.1002/jmrs.145

[3] ZONG D, YIN L, ZHONG Q, GUO WJ, XU JH et al. ZNF488 Enhances the Invasion and Tumorigenesis in Nasopharyngeal Carcinoma Via the Wnt Signaling Pathway Involving Epithelial Mesenchymal Transition. Cancer Res Treat 2016; 48: 334-344. https://doi.org/10.4143/crt.2014.311

[4] YANG L, HONG S, WANG Y, CHEN H, LIANG S et al. Development and External Validation of Nomograms for Predicting Survival in Nasopharyngeal Carcinoma Patients after Definitive Radiotherapy. Sci Rep 2015; 5: 15638. https:// doi.org/10.1038/srep15638

[5] CHUA ML, WEE JT, HUI EP, CHAN AT. Nasopharyngeal carcinoma. Lancet 2016; 387: 1012-1024. https://doi. org/10.1016/S0140-6736(15)00055-0

[6] STUART PE, NAIR RP, TSOI LC, TEJASVI T, DAS S et al. Genome-wide Association Analysis of Psoriatic Arthritis and Cutaneous Psoriasis Reveals Differences in Their Genetic Architecture. Am J Hum Genet 2015; 97: 816-836. https:// doi.org/10.1016/j.ajhg.2015.10.019

[7] MURAKAWA Y, HINZ M, MOTHES J, SCHUETZ A, UHL M et al. RC3H1 post-transcriptionally regulates $\mathrm{A} 20 \mathrm{mRNA}$ and modulates the activity of the IKK/NF-kappaB pathway. Nat Commun 2015; 6: 7367. https://doi.org/10.1038/ncomms8367 
[8] TAKEUCHI M, KASTNER DL, REMMERS EF. The immunogenetics of Behcet's disease: A comprehensive review. J Autoimmun 2015; 64: 137-148. https://doi.org/10.1016/j. jaut.2015.08.013

[9] THEWES V, ORSO F, JAGER R, ECKERT D, SCHAFER S et al. Interference with activator protein-2 transcription factors leads to induction of apoptosis and an increase in chemo- and radiation-sensitivity in breast cancer cells. BMC Cancer 2010; 10: 192. https://doi.org/10.1186/1471-2407-10-192

[10] CHEN S, XING H, LI S, YU J, LI H et al. Up-regulated A20 promotes proliferation, regulates cell cycle progression and induces chemotherapy resistance of acute lymphoblastic leukemia cells. Leuk Res 2015; 39: 976-983. https://doi. org/10.1016/j.leukres.2015.06.004

[11] CHEN H, HU L, LUO Z, ZHANG J, ZHANG C et al. A20 suppresses hepatocellular carcinoma proliferation and metastasis through inhibition of Twist1 expression. Mol Cancer 2015; 14: 186. https://doi.org/10.1186/s12943-015-0454-6

[12] DING Z, XU F, TANG J, LI G, JIANG P et al. Physcion 8-O-beta-glucopyranoside prevents hypoxia-induced epithelial-mesenchymal transition in colorectal cancer HCT116 cells by modulating EMMPRIN. Neoplasma 2016; 63: 351-361. https://doi.org/10.4149/303 150723N405

[13] XU J, DAI A, CHEN Q, LIU X, ZHANG Y et al. Genetic regulation analysis reveals involvement of tumor necrosis factor and alpha-induced protein 3 in stress response in mice. Gene 2016; 576: 528-536. https://doi.org/10.1016/j.gene.2015.10.071

[14] LANGSCH S, BAUMGARTNER U, HAEMMIG S, SCHLUP C, SCHAFER, SC et al. miR-29b Mediates NF-kappaB Signaling in KRAS-Induced Non-Small Cell Lung Cancers. Cancer Res 2016; 76: 4160-4169. https://doi.org/10.1158/0008-5472. CAN-15-2580

[15] ANDO M, SATO Y, TAKATA K, NOMOTO J, NAKAMURA S ET AL. A20 (TNFAIP3) deletion in Epstein-Barr virus-associated lymphoproliferative disorders/lymphomas. PLoS One 2013; 8: e56741. https://doi.org/10.1371/journal. pone.0056741

[16] VAN DE LAAR L, COFFER PJ, WOLTMAN AM. Regulation of dendritic cell development by GM-CSF: molecular control and implications for immune homeostasis and therapy. Blood 2012; 119: 3383-3393. https://doi.org/10.1182/ blood-2011-11-370130

[17] MAO D, QIAO L, LU H, FENG Y. B-cell translocation gene 3 overexpression inhibits proliferation and invasion of colorectal cancer SW480 cells via Wnt/beta-catenin signaling pathway. Neoplasma 2016; 63: 705-716. https://doi.org/10.4149/ neo 2016507

[18] WANG H, SANG M, GENG C, LIU F, GU L et al. MAGE$\mathrm{A}$ is frequently expressed in triple negative breast cancer and associated with epithelial-mesenchymal transition. Neoplasma 2016; 63: 44-56. https://doi.org/10.4149/ neo 2016006

[19] GAO ZW, WANG HP, DONG K, LIN F, WANG X et al. Adenosine inhibits migration, invasion and induces apoptosis of human cervical cancer cells. Neoplasma 2016; 63: 201-207. https://doi.org/10.4149/204 150723n407

[20] DIEPENBRUCK M, CHRISTOFORI G. Epithelial-mesenchymal transition (EMT) and metastasis: yes, no, maybe? Curr Opin Cell Biol 2016; 43: 7-13. https://doi.org/10.1016/j. ceb.2016.06.002

[21] OHLMANN A, SCHOLZ M, KOCH M, TAMM ER. Epithelial-mesenchymal transition of the retinal pigment epithelium causes choriocapillaris atrophy. Histochem Cell Biol 2016; 146: 769-780. https://doi.org/10.1007/s00418016-1461-4

[22] GRANT CM, KYPRIANOU N. Epithelial mesenchymal transition (EMT) in prostate growth and tumor progression. Transl Androl Urol 2013; 2: 202-211 
A

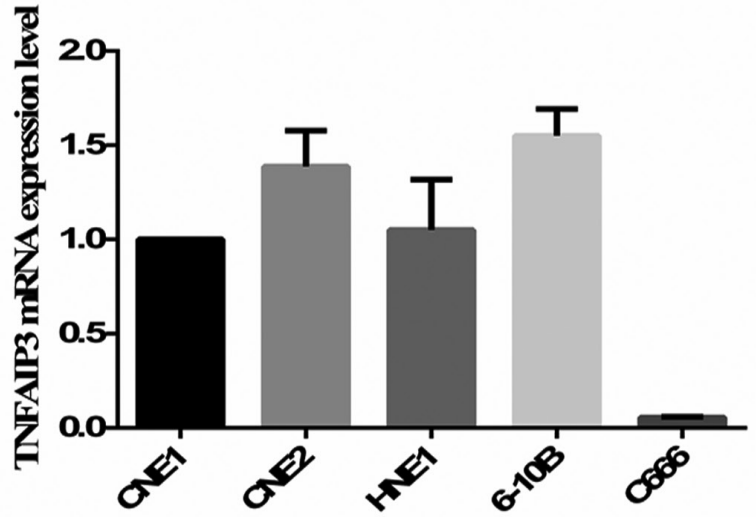

B

CNE1 CNE2 HNE1 6-10B C666

TNFAIP3

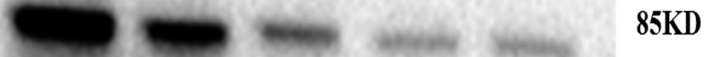

actin

$45 \mathrm{KD}$

C

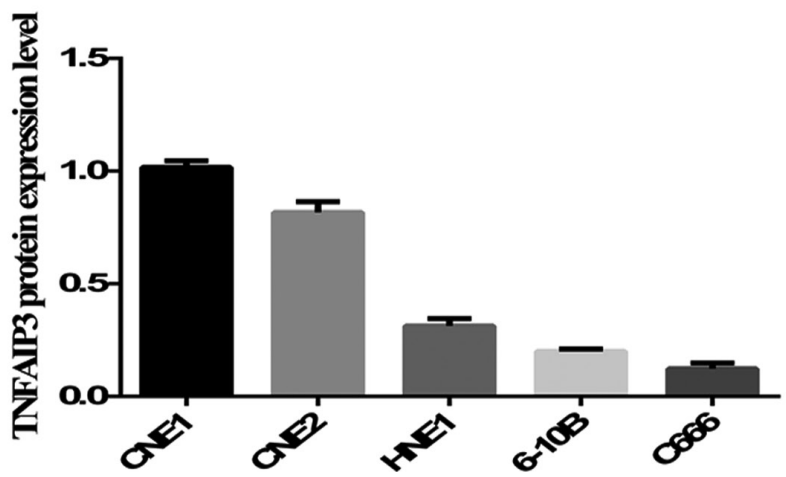

Supplementary Figure 1, TNFAIP3 expression levels in NPC. (A) TNFAIP3 mRNA expression levels in NPC. (B) TNFAIP3 protein expression levels in NPC 
Supplementary Table 1. Correlation between the expression of TNFAIP3 and clinical features

\begin{tabular}{|c|c|c|c|c|}
\hline & & \multicolumn{2}{|c|}{ TNFAIP3 expression level } & \multirow[b]{2}{*}{$P$ value } \\
\hline & All cases & Low expression & High expression & \\
\hline \multicolumn{5}{|l|}{ Gender } \\
\hline Female & 88 & 30 & 58 & 0.374 \\
\hline Male & 233 & 92 & 141 & \\
\hline \multicolumn{5}{|c|}{ Age at diagnosis } \\
\hline$\leq 61$ & 170 & 67 & 103 & 0.582 \\
\hline$>61$ & 151 & 55 & 96 & \\
\hline \multicolumn{5}{|c|}{ T classificaction } \\
\hline $\mathrm{T}_{1}-\mathrm{T}_{2}$ & 112 & 46 & 66 & 0.408 \\
\hline $\mathrm{T}_{3}-\mathrm{T}_{4}$ & 209 & 76 & 133 & \\
\hline \multicolumn{5}{|c|}{$\mathrm{N}$ classificaction } \\
\hline $\mathrm{N}_{1-2}$ & 220 & 84 & 136 & 0.924 \\
\hline $\mathrm{N}_{2-3}$ & 101 & 38 & 63 & \\
\hline Clinical & TNM & & & \\
\hline \multicolumn{5}{|l|}{ Staging } \\
\hline$|-| \mid$ & 74 & 31 & 43 & 0.432 \\
\hline III-IV & 247 & 91 & 156 & \\
\hline \multicolumn{5}{|c|}{ perineural invasion } \\
\hline NO & 170 & 63 & 107 & 0.711 \\
\hline YES & 151 & 59 & 92 & \\
\hline \multicolumn{5}{|c|}{$\begin{array}{l}\text { Neoplasm histologic } \\
\text { grade }\end{array}$} \\
\hline $\mathrm{G}_{1}-\mathrm{G}_{2}$ & 242 & 85 & 157 & 0.063 \\
\hline $\mathrm{G}_{3}-\mathrm{G}_{4}$ & 79 & 37 & 42 & \\
\hline
\end{tabular}

